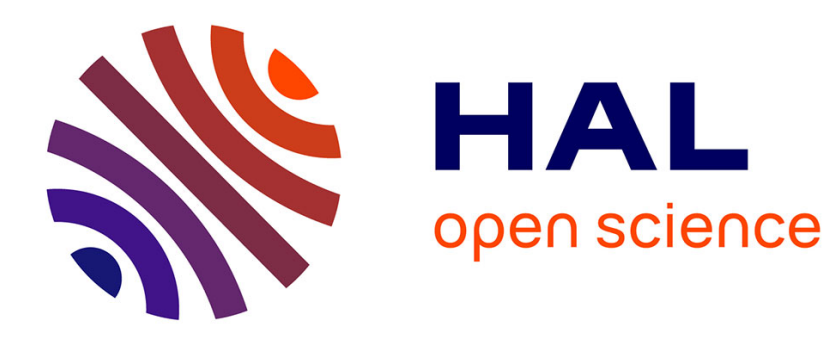

\title{
Volatility persistence in crude oil markets
}

Amélie Charles, Olivier Darné

\section{To cite this version:}

Amélie Charles, Olivier Darné. Volatility persistence in crude oil markets. Energy Policy, 2014, 65, pp.729-742. 10.1016/j.enpol.2013.10.042 . hal-00940312

\section{HAL Id: hal-00940312 \\ https://hal-audencia.archives-ouvertes.fr/hal-00940312}

Submitted on 5 Feb 2014

HAL is a multi-disciplinary open access archive for the deposit and dissemination of scientific research documents, whether they are published or not. The documents may come from teaching and research institutions in France or abroad, or from public or private research centers.
L'archive ouverte pluridisciplinaire HAL, est destinée au dépôt et à la diffusion de documents scientifiques de niveau recherche, publiés ou non, émanant des établissements d'enseignement et de recherche français ou étrangers, des laboratoires publics ou privés. 


\title{
Volatility Persistence in Crude Oil Markets
}

\author{
Amélie CHARLES* \\ Audencia Nantes, School of Management
}

Olivier DARNÉ ${ }^{\dagger}$

LEMNA, University of Nantes

February 4, 2014

\begin{abstract}
Financial market participants and policy-makers can benefit from a better understanding of how shocks can affect volatility over time. This study assesses the impact of structural changes and outliers on volatility persistence of three crude oil markets - Brent, West Texas Intermediate (WTI) and Organization of Petroleum Exporting Countries (OPEC) - between January 2, 1985 and June 17, 2010. Firstly, we identify the time points at which structural changes occurred using the modified ICSS test developed by Sansó et al. (2004) and then incorporate this information into the volatility modeling. Our results indicated that the degree of persistence of volatility is reduced by incorporating the variance changes into the volatility model. Secondly, we identify outliers using intervention analysis and conditional heteroscedasticity model. These large shocks can be associated with particular event patterns, such as the invasion of Kuwait by Iraq, the Operation Desert Storm, the Operation Desert Fox, and the Global Financial Crisis as
\end{abstract}

${ }^{*}$ Audencia Nantes, School of Management, 8 route de la Jonelière, 44312 Nantes, France. Email: acharles@audencia.com.

${ }^{\dagger}$ Corresponding author: LEMNA, University of Nantes, IEMN-IAE, Chemin de la Censive du Tertre, BP 52231, 44322 Nantes, France. Email: olivier.darne@ univ-nantes.fr. 
well as OPEC announcements on production reduction or US announcements on crude inventories. We find that the crude oil markets are more affected by outliers and patches of outliers than by variance changes. We also show that outliers can bias the estimation of the persistence of the volatility. Taking into account outliers on the volatility modelling process improve the understanding of volatility in crude oil markets.

Keywords: Crude oil; volatility persistence; structural breaks; outliers; GARCH.

JEL Classification: C12, C53, G01, G10. 


\section{Introduction}

The price of crude oil is one of the world's most important global economic indicators. Policy-makers, producers, consumers and financial participants monitor its behavior. Since the end of the 1990s oil prices have been steadily increasing, reflecting rising demand for crude oil, particularly from developing nations. Oil prices have been very volatile, changing their trajectories and behavior with respect to the economic situation. Understanding the behavior of volatility in crude oil prices is important for pricing financial assets, for implementing hedging strategies and for assessing regulatory proposals to restrict international capital flows. For examples, changes in volatility can affect the risk exposure of producers and industrial consumers of oil. These changes may alter their respective investments in oil inventories and facilities for production and transportation.

Crude oil prices are characterized by high volatility and some drastic shocks, such as the day Operation Desert Storm with a negative return of $-42 \%$ for WTI (Askari and Krichene, 2008; Larsson and Nossman, 2011). Financial market participants and policy-makers can benefit from a better understanding of how shocks can affect volatility over time, especially whether the shocks are persistent or short lived. Autoregressive conditionally heteroscedastic (ARCH) models introduced by Engle (1982) and extended to generalized ARCH (GARCH) by Bollerslev (1986), have been developed to capture the two most important stylized facts of returns of financial assets, which are heavy-tailed distribution and volatility clustering. According to these models, the information available in a period is important for predicting future variance. It is interesting to consider how the available information affects forecast uncertainty as the forecast horizon increases; in other words, the degree of persistence. Persistence in the variance of a random variable evolving through time refers to the property of momentum in conditional variance; past volatility explains current volatility.

As underlined by Aragó and Fernandez-Izquierdo (2003), the degree of persistence of the variance has evident economic implications, arising from the effect that this 
aspect has on the predictability of their future value. Poterba and Summers (1986) argue that, for multiperiod assets such as stocks, shocks have to persist for a long time for a time-varying risk premium to be able to explain the large fluctuations observed in the stock market. Likewise, this aspect is important in the valuation of options, since the shocks that permanently influence the variance will affect their price to a greater degree than those that are temporary. This aspect can have a direct influence on dynamic hedging policies that try to minimize the risk of the hedged position with futures contracts, since the value of that ratio will depend on the capacity to predict the variance of the futures contract correctly (Wilson et al., 1996). Traders who participate in both the cash and futures markets choose a hedging strategy that reflects their risk and return preferences. The risk and return of the portfolio depend on the hedge ratio. An optimal hedge ratio is one that minimizes the variance of the hedged portfolio return. The time-varying hedge strategy depends critically on the predictability of the future variances and, consequently, assumes no sudden changes in the variance of the series.

However, financial markets are periodically subject to sudden large shocks, such as the financial crisis. These types of shocks can cause abrupt breaks in the unconditional variance of returns and are equivalent to structural breaks in the parameters of the GARCH processes governing the conditional volatility of returns. It is well know that these shocks can bias the estimated persistence of volatility (see, e.g., Lamoureux and Lastrapes, 1990; Mikosch and Starica, 2004; Hillebrand, 2005; Krämer and Azamo, 2007). A relatively recent approach to test for volatility shifts is the iterative cumulative sums of squares (ICSS) algorithm (Inclán and Tiao, 1994; Sansó et al., 2004). This algorithm allows for detecting multiple breakpoints in variance and has been extensively used for identifying changes in the volatility of financial time series (Hammoumdeh and Li, 2008; Kasman, 2009; Wang and Moore, 2009, among others).

To the best of our knowledge, Wilson et al. (1996), Ewing and Malik (2010), Kang et al. (2011), Vivian and Wohar (2012) and Arouri et al. (2012) are the only studies 
that analyze sudden changes in oil prices from the ICSS algorithm 11 They find mixed results on the presence or not of variance changes in crude oil markets. Recently, Rodrigues and Rubia (2011) study the size properties of ICSS algorithm for detecting structural breaks in variance under the hypothesis of additive outliers, which are usually present in financial time series (e.g., Charles and Darné, 2005; Bali and Guirguis, 2007). Their results indicate that neglected outliers tend to bias the ICSS test. In this paper we thus detect outliers in the crude oil returns before we attempt to identify the variance changes. The large shocks in volatility of the Brent, OPEC and WTI crude oil prices are identified from intervention analysis based on a conditional heteroscedasticity model proposed by Franses and Ghijsels (1999). We determine when these (positive and negative) large changes in volatility of daily returns occur. We try to associate the date of each additive outlier with a specific (economic, political or financial) event that occurred near that date, and many of them seem to be associated with the same event patterns. We find that large shocks in volatility of the crude oil prices are principally due to the Iran-Irak war, the invasion of Kuwait by Iraq, the Operation Desert Storm, the Operation Desert Fox, and the Global Financial Crisis as well as OPEC announcements on production reduction or US announcements on crude inventories. We use the modified ICSS test proposed by Sansó et al. (2004) to identify breakpoints and sudden shifts in volatility and do not find structural breaks in the volatility when taking into account these large shocks. Finally, we investigate the degree of persistence of the three oil markets by comparing estimates of different GARCH models which capture short and long memory (GARCH, IGARCH, FIGARCH and HYGARCH) from three ways: (1) original data; (2) original data with structural breaks; and (3) outlier-adjusted data. The results show the importance to take into account the large shocks in modelling volatility of crude oil returns.

\footnotetext{
${ }^{1}$ Fong and See $(2002,2003)$ and Vo (2009) model conditional volatility of crude oil futures prices with a Markow switching GARCH model and find regime shifts. In our paper, we detect the shift points in (unconditional) variance, not the probabilities associated with those shifts and without restricting the number of regimes to two as in the Markov switching model.
} 
This article is organized as follows. The literature review is given in Section 2. Section 3 describes the sequential procedure for detecting outliers in crude oil prices, and the modified ICSS algorithm used to identify sudden variance breaks in crude oil prices. The data set is presented in Section 4. The empirical results on outliers and variance changes are discussed in Section 5. Section 6 displays the study of the degree of persistence. Finally, Section 7 concludes.

\section{Literature review}

Wilson et al. (1996), Ewing and Malik (2010), Kang et al. (2011), Vivian and Wohar (2012) and Arouri et al. (2012) are the only studies that analyze sudden changes in oil prices from the ICSS algorithm. Wilson et al. (1996) examine daily data of oil futures and oil-producing companies from January 1, 1984 to December 31, 1992 using the original ICSS algorithm developed by Inclán and Tiao (1994). They document sudden changes in the unconditional variance of oil future returns and relate them to surrounding major events. They also report that shocks are less persistent and have less initial impact when structural breaks are accounted for within a simple ARCH model. Kang et al. (2011) also use the original ICSS algorithm to identify structural changes in volatility of WTI and Brent crude oil prices spanning from January 5, 1990 to March 27, 2009. They find five structural change points, which are correlated with global economic and political events, such as Iraqi invasion of Kuwait, Gulf War, or the Global Financial Crisis. They show that the degree of volatility persistence is overestimated when ignoring regime shifts in variance. Arouri et al. (2012) apply the original ICSS algorithm on WTI crude oil prices over the period from January 2, 1986 to March 15, 2011, but they do not find structural break in the unconditional variance dynamics.

The original ICSS algorithm used in the previous studies is designed for i.i.d. processes, which is a very strong assumption for financial data, in which there is evidence of conditional heteroskedasticity. Sansó et al. (2004) show that the size distortions are important for heteroskedastic conditional variance processes from 
Monte carlo simulations. Their results thus invalidate in practice the use of the original ICSS algorithm for financial time series. To overcome this problem, the authors propose a new test that explicitly consider the fourth moment properties of the disturbances and the conditional heteroskedasticity ${ }^{2}$ Ewing and Malik (2010) examine daily WTI crude oil prices from July 1, 1993 to June 30, 2008, by using this modified ICSS algorithm to identify structural breaks in volatility of oil prices. They identify three break points and find that oil shocks dissipate very quickly but have a strong initial impact. Vivian and Wohar (2012) also use the modified ICSS algorithm to analyze daily WTI and Brent crude oil prices from January 2, 1985 to July 30, 2010. They find three structural breaks in volatility of Brent and that the decline in persistence is much smaller than Ewing and Malik (2010) find 3 In contrast to Ewing and Malik (2010) they find no structural break in WTI.

\section{Methodology}

\subsection{Outlier detection in GARCH models}

Several studies have showed that financial data may be affected by contaminated observations (Balke and Fomby, 1994; Charles and Darné, 2005). This type of observations, called outliers, reflects extraordinary, infrequently occurring events or shocks that have important effects on macroeconomic and financial time series. There are several methods for detecting outliers in nonlinear setting (Hotta and Tsay, 1998; Sakata and White, 1998; Franses and Ghijsels, 1999; Franses and van Dijk, 2000; Charles and Darné, 2005; Doornik and Ooms, 2005; Zhang and King, 2005) based on intervention analysis as originally proposed by Box and Tiao (1975). Here we use the method proposed by Franses and Ghijsels (1999), which extends the outlier detection procedure in ARMA (linear) models developed by Chen and Liu (1993) to GARCH

\footnotetext{
${ }^{2}$ This adjusted statistic is equivalent to the non-parametric test proposed by Kokoszka and Leipus (2000).

${ }^{3}$ Note that Ewing and Malik (2010) and Vivian and Wohar (2012) do not attempt to identify the causes of the break points.
} 
models, to take into account the events that cause an immediate, one-shot effect on the observed series, called additive outlier (AO). This method allows us to examine the large shocks that affected the crude oil returns.

Consider the returns series $\varepsilon_{t}$, which is defined by $\varepsilon_{t}=\log P_{t}-\log P_{t-1}$, where $P_{t}$ is the observed price at time $t$, and consider the $\operatorname{GARCH}(1,1)$ model

$$
\begin{aligned}
\varepsilon_{t} & =z_{t} \sqrt{h_{t}}, \\
\varepsilon_{t} & \sim N\left(0, \sqrt{h_{t}}\right), \quad z_{t} \sim \text { i.i.d.N }(0,1), \\
h_{t} & =\alpha_{0}+\alpha_{1} \varepsilon_{t-1}^{2}+\beta_{1} h_{t-1}
\end{aligned}
$$

where $\alpha_{0}>0, \alpha_{1} \geq 0, \beta_{1} \geq 0$ and $\alpha_{1}+\beta_{1}<1$, such that the model is covariancestationary. The $\operatorname{GARCH}(1,1)$ model can be rewritten as an $\operatorname{ARMA}(1,1)$ model for $\varepsilon_{t}^{2}$ (see Bollerslev, 1986)

$$
\varepsilon_{t}^{2}=\alpha_{0}+\left(\alpha_{1}+\beta_{1}\right) \varepsilon_{t-1}^{2}+v_{t}-\beta_{1} v_{t-1}
$$

where $v_{t}=\varepsilon_{t}^{2}-h_{t}$. The additive outliers (AO) can be modelled by regression polynomials as follows:

$$
e_{t}^{2}=\varepsilon_{t}^{2}+\omega \xi(B) I_{t}(\tau)
$$

where $\varepsilon_{t}$ is a $\mathrm{GARCH}(1,1)$ process, $\xi(B)=1$ is the polynomial characterizing the $\mathrm{AO}$ occurring at time $t=\tau, \omega$ represents its impact on the series and $I_{t}(\tau)$ is an indicator function with the value of 1 at time $t=\tau$ and 0 otherwise.

A GARCH $(1,1)$ model is fitted to $\varepsilon_{t}$ in $(9)$ and the residuals are obtained:

$$
\eta_{t}=\frac{-\alpha_{0}}{1-\beta_{1} B}+\pi(B) e_{t}^{2}=v_{t}+\pi(B) \xi(B) \omega I_{t}(\tau)
$$

where $\pi(B)=\left(1-\left(\alpha_{1}+\beta_{1}\right) B\right)\left(1-\beta_{1} B\right)^{-1}$. The expression (5) can be interpreted as a regression model for $\eta_{t}$, i.e.

$$
\eta_{t}=\omega x_{t}+v_{t}
$$

with $x_{t}=0$ for $t<\tau, x_{t}=1$ for $t=\tau$, and $x_{\tau+k}=-\pi_{k}$ (for $t>\tau$ and $k>0$.

The detection of the outliers is based on likelihood ratio statistics, given by:

$$
\hat{\tau}=\left(\hat{\omega}(\tau) / \hat{\sigma}_{v}\right)\left(\sum_{t=\tau}^{n} x_{t}^{2}\right)^{1 / 2} \quad \text { with } \hat{\omega}(\tau)=\left(\sum_{t=\tau}^{n} x_{t} \eta_{t}\right)\left(\sum_{t=\tau}^{n} x_{t}^{2}\right)^{-1}
$$


where $\hat{\omega}(\tau)$ denotes the estimation of the outlier impact at time $t=\tau$, and $\hat{\sigma}_{v}^{2}$ is the estimated variance of the residual process.

Outliers are identified through running a sequential detection procedure, consisting of an outer and an inner iteration. In the outer iteration, assuming that there are no outliers, a $\operatorname{GARCH}(1,1)$ model is estimated, obtaining the residuals. The results from the outer iteration are then used in the inner iteration to identify outliers. The likelihood ratio test statistics are calculated for each observations. The largest absolute value of these test statistics $\hat{\tau}_{\max }=\max _{1 \leq \tau \leq n}|\hat{\tau}|$ is compared to a pre-specified critical value (based on simulation experiments), and if the test statistic is larger, an outlier is found at time $t=\tau$. When an outlier is detected, the effect of the outlier is removed from the data as follows: the observation $e_{t}$ is adjusted at time $t=\tau$ to obtain the corrected $\varepsilon_{t}^{*}$ via (4) using the $\hat{\omega}$, i.e. $\varepsilon_{t}^{*}=e_{t}-\hat{\omega} \xi I_{t}(\tau)$. This process is repeated until no more outliers can be found. Next, return to the outer iteration in which the GARCH model is reestimated, using the corrected data, and start the inner iteration again. This procedure is repeated until no outlier is found.

\subsection{Sudden change detection}

The most popular statistical methods specifically designed to detect breaks in volatility are CUSUM-type tests. As underlined by Rodrigues and Rubia (2011), the ability of the CUSUM tests to identify structural changes depends of the underlying assumptions. Financial data display a time varying volatility pattern, known as volatility clustering. Andreou and Ghysels (2002) illustrate the pervasive effect of persistent volatility on CUSUM-type tests experimentally. Their results indicate that the Kokoszka and Leipus (2000) test is robust to conditional heteroscedasticity. Sansó et al. (2004) propose a more general test than that of Kokoszka and Leipus (2000) based on the iterative cumulative sum of squares (ICSS) algorithm developed by Inclán and Tiao (1994).

Let $e_{i, t}=100 \times \log \left(P_{i, t} / P_{i, t-1}\right)$, where $P_{i, t}$ is the price of the index $i$ at the time $t$, so that $e_{t}$ is the percent return of the index $i$ from period $t-1$ to $t$. $\left\{e_{t}\right\}$ is then assumed 
to be a series of independent observations from a normal distribution with zero mean and unconditional variance $\sigma_{t}^{2}$ for $t=1, \ldots, T$. Assume that the variance within each interval is denoted by $\sigma_{j}^{2}, j=0,1, \ldots, N_{T}$, where $N_{T}$ is the total number of variance changes and $1<\kappa_{1}<\kappa_{2}<\cdots<\kappa_{N_{T}}<T$ are the set of breakpoints. Then the variances over the $N_{T}$ intervals are defined as

$$
\sigma_{t}^{2}= \begin{cases}\sigma_{0}^{2}, & 1<t<\kappa_{1} \\ \sigma_{1}^{2}, & \kappa_{1}<t<\kappa_{2} \\ \ldots & \\ \sigma_{N_{T}}^{2}, & \kappa_{N_{T}}<t<T\end{cases}
$$

The cumulative sum of squares is used to estimate the number of variance changes and to detect the point in time of each variance shift. The cumulative sum of the squared observations from the beginning of the series to the $k$ th point in time is expressed as $C_{k}=\sum_{t=1}^{k} e_{t}^{2}$ for $k=1, \ldots, T$. To test the null hypothesis of constant unconditional variance, the Inclán-Tiao statistic is given by:

$$
I T=\sup _{k}\left|(T / 2)^{0.5} D_{k}\right|
$$

where $D_{k}=\left(\frac{C_{k}}{C_{T}}\right)-\left(\frac{k}{T}\right)$, with $C_{T}$ is the sum of the squared residuals from the whole sample period. The value of $k$ that maximizes $\left|(T / 2)^{0.5} D_{k}\right|$ is the estimate of the break date. The ICSS algorithm systematically looks for breakpoints along the sample. If there are no variance shifts over the whole sample period, $D_{k}$ will oscillate around zero. Otherwise, if there are one or more variance shifts, $D_{k}$ will deviate from zero. The asymptotic distribution of the $I T$ statistic is given by $\sup _{r}\left|W^{*}(r)\right|$, where $W^{*}(r)=W(r)-r W(1)$ is a Brownian bridge and $W(r)$ is standard Brownian motion. Finite-sample critical values can be generated by simulation.

The $I T$ statistic is designed for i.i.d. processes, which is a very strong assumption for financial data, in which there is evidence of conditional heteroscedasticity. Sansó et al. (2004) show that the size distortions are important for heteroscedastic conditional variance processes from Monte Carlo simulations. Their results thus invalidate the practical use of this test for financial time series. To overcome this problem, Sansó et 
al. (2004) propose a new test that explicitly consider the fourth moment properties of the disturbances and the conditional heteroscedasticity ${ }^{4}$ They propose a nonparametric adjustment to the $I T$ statistic that allows $e_{t}$ to obey a wide class of dependent processes under the null hypothesis. Consistent with Sansó et al. (2004), we use a non-parametric adjustment based on the Bartlett kernel, and the adjusted statistic ${ }^{5}$ is given by:

$$
A I T=\sup _{k}\left|T^{-0.5} G_{k}\right|
$$

where $G_{k}=\hat{\lambda}^{-0.5}\left[C_{k}-\left(\frac{k}{T}\right) C_{T}\right], \hat{\lambda}=\hat{\gamma}_{0}+2 \sum_{l=1}^{m}\left[1-l(m+1)^{-1}\right] \hat{\gamma}_{l}, \hat{\gamma}_{l}=T^{-1} \sum_{t=l+1}^{T}\left(e_{t}^{2}-\right.$ $\left.\hat{\sigma}^{2}\right)\left(e_{t-l}^{2}-\hat{\sigma}^{2}\right), \hat{\sigma}^{2}=T^{-1} C_{T}$, and the lag truncation parameter $m$ is selected using the procedure in Newey and West (1994). Under general conditions, the asymptotic distribution of AIT statistic is also given by $\sup _{r}\left|W^{*}(r)\right|$, and finite-sample critical values can be generated by simulation.

\section{Data and summary statistics}

The data of the study consists of the daily closing spot prices for three oil crude markets: the US West Texas Intermediate (WTI), the UK Brent, and the Organization of the Petroleum Exporting Countries (OPEC) markets. The data comes from Thomson Financial Datastream and is given in US dollar per barrel. The data spans from 1 January, 1985 to 17 June, 2011, namely 6905 observations. Figure 1 provides a graphical representation of these series.

Table 1 presents summary statistics for the WTI, OPEC and Brent crude oil returns calculated as the first differences in the logs of the spot prices. The WTI and Brent

\footnotetext{
${ }^{4}$ Bacmann and Dubois (2002) show that one way to circumvent this problem is by filtering the return series by a GARCH $(1,1)$ model, and applying the ICSS algorithm developed by Inclán and Tiao (1994) to the standardized residuals obtained from the estimation. Fernandez (2006) proposes an alternative approach to testing for variance homogeneity based on wavelet analysis.

${ }^{5}$ This adjusted statistic is equivalent to the non-parametric test proposed by Kokoszka and Leipus (2000).
} 
markets have approximately equal mean returns of about $0.05 \%$ per day, with the Brent returns marginally smaller than the WTI returns. These two crude oil markets display higher mean returns than the OPEC market ( $0.04 \%$ per day) but they are also slightly more volatile, measured by standard deviation $(0.024$ versus 0.020$)$. All the returns are highly non-normal, i.e. showing evidence of significant negative skewness and excess kurtosis, as might be expected from daily returns. All series are leptokurtic (i.e., fat-tailed distribution) and thus the variance of the crude oil prices is principally due to infrequent but extreme deviations. The Lagrange Multiplier test for the presence of the ARCH effect indicates clearly that all crude oil prices show strong conditional heteroscedasticity, which is a common feature of financial data. In other words, there are quiet periods with small price changes and turbulent periods with large oscillations. The outlier-adjusted returns also exhibit excess skewness, excess kurtosis and conditional heteroscedasticity, although the excess kurtosis decreases dramatically, except for the OPEC returns that do not display excess skewness. As shown by Carnero et al. (2001) and Charles and Darné (2005), this result show that outliers may cause significant skewness.

\section{Large shocks in crude oil volatility}

\subsection{Outliers in crude oil returns}

Tables $2+3$ give the identified outliers in the returns of the three crude oil markets in chronological order. In addition, we also associate the date corresponding to each outlier to a specific (economic, political or financial) event that occurred near that date. As expected, outliers have been detected in all the series, giving strong proof of infrequent large shocks. This finding shows the importance to take into account these large shocks in modelling volatility of returns of the crude oil markets. Given the clustering of outliers across series, i.e. an event can cause infrequent large shocks in different crude oil markets, we describe the economic events that could affect the series chronologically. 
We find patches of outliers due to the Iran-Irak war in March-April and July-August 1986, the invasion of Kuwait by Iraq in August 1990, the Operation Desert Storm in January 1991, the Operation Desert Fox in December 1998, and the Global Financial Crisis in December 2008 and January 2009. Most of individual outliers are due to OPEC announcements, especially production reduction. Hyndman (2008), Lin and Tamvakis (2010) and Demirer and Kutan (2010) also find that OPEC production cut announcements have an impact on crude oil prices, using event-study methodology. More specifically, the WTI returns are affected by US announcements on crude inventories. Indeed, most WTI crude oil gets refined in the Midwest region of the US, more precisely at Cushing (Oklahoma), with some more refined within the Gulf Coast region. Therefore, the WTI price can be affected by its storage tank capacity and its infrastructure logistics (Horsnell and Mabro, 1993).

\subsection{Sudden changes in crude oil volatility}

Rodrigues and Rubia (2011) discuss the effects that sample contamination has on the asymptotic properties of CUSUM-type tests for detecting change points in variance and characterize the finite sample behavior by means of Monte Carlo simulations. They focus on additive outliers, that is exogenous changes that directly affect the series, which prove able to generate large size distortions in these tests. The authors show that the Sansó et al. (2004) test exhibits low power and tends to find few or no breaks at all. As suggested by Rodrigues and Rubia (2011), we apply the modified ICSS algorithm to detect sudden changes in volatility of crude oil prices, using the outlier-corrected return series 6

The time periods of a shift in volatility as detected by the modified ICSS algorithm are given in Table 4. This ICSS algorithm identifies variance breaks in the Brent and OPEC crude oil markets, with two and four shifts, respectively, but not for the WTI crude oil market from non-adjusted data. However, we do not find variance changes

\footnotetext{
${ }^{6}$ Further, Inclán and Tiao (p.917, 1994) advised that "it is advisable to complement the search for variance changes with a procedure for outlier detection".
} 
when the modified ICSS algorithm is applied on outlier-adjusted data. This finding can be explained by the presence of outliers in crude oil markets, especially by patches of outliers. For example, the change break detected in the OPEC market in July 1990 is just before a few outliers due to the invasion of Kuwait by Iraq in August 1990. The variance break in the Brent and OPEC markets in March-April 1991 is just after a few outliers due to the Operation Desert Storm in January 1991. These results confirm that the ICSS algorithm is biased by the presence of outliers, and show that the crude oil markets are more affected by outliers and patches of outliers than by variance changes.

\section{Degree of persistence}

With the availability of high frequency date for financial markets analysis there has been an increase in studies dealing with the persistence of shocks on the variance of financial instrument returns. As underlined by Aragó and Fernandez-Izquierdo (2003), the degree of persistence of the variance has evident economic implications, arising from the effect that this aspect has on the predictability of their future value. The persistence features the degree to which past volatility explains current volatility. Although volatility clearly fluctuates over time, an important question is "how persistent are these changes in volatility following some shock?"

There are by now several alternative GARCH type models that attempt to take volatility persistence appropriately into account, implying quite different measures for the conditional volatility. In this paper we consider four volatility models: the Generalized ARCH model (GARCH), the Integrated GARCH model, the Fractionaly IGARCH (FIGARCH) model, and the hyperbolic GARCH (HYGARCH) model which are intensively used in the literature to investigate the persistence of shocks in crude oil markets (e.g., Wei et al., 2010; Kang et al., 2011; Arouri et al., 2012) 7

\footnotetext{
${ }^{7} \mathrm{We}$ will concern ourselves in this paper only with the volatility of univariate series. We will focus on the volatility of asset returns and consequently will pay very little attention to expected returns. Note that mispecification of the conditional mean equation appears to have very little influence on the estimated conditional variance in continuous (Nelson, 1990a and 1990b) as well as discrete time (McKenzie, 1997).
} 


\subsection{The GARCH models}

The GARCH model was developed independently by Bollerslev (1986) and Taylor (1986). The GARCH model allows the conditional variance to be dependent upon previous own lags.

Consider the returns series $\varepsilon_{t}$, which is defined by $\varepsilon_{t}=\log P_{t}-\log P_{t-1}$, where $P_{t}$ is the observed price at time $t$, and consider the $\operatorname{GARCH}(p, q)$ model

$$
\begin{aligned}
& \varepsilon_{t}=z_{t} \sqrt{\sigma_{t}^{2}} \\
& \varepsilon_{t} \sim N\left(0, \sqrt{\sigma_{t}^{2}}\right), \quad z_{t} \sim \text { i.i.d.N }(0,1), \\
& \sigma_{t}^{2}=\omega+\alpha(L) \varepsilon_{t}^{2}+\beta(L) \sigma_{t}^{2}
\end{aligned}
$$

where $L$ is the lag operator, $\alpha(L)=\sum_{i=1}^{q} \alpha_{i} L^{i}, \beta(L)=\sum_{j=1}^{p} \beta_{j} L^{j}$. The parameters should satisfy $\omega>0, \alpha_{i} \geq 0$ and $\beta_{j} \geq 0$ to guarantee the positivity of the conditional variance 8

The stationary of the process is achieved when the restriction $\sum_{i}^{q} \alpha_{i}+\sum_{j}^{p} \beta_{j}<1$ is satisfied. Ling and McAleer (2002a, 2002b) have derived the regularity conditions of a $\operatorname{GARCH}(1,1)$ model, defined as follows: $E\left[\varepsilon_{t}^{2}\right]=\alpha_{1}+\beta_{1}<1$ and $E\left[\varepsilon_{t}^{4}\right]=$ $3 \alpha_{1}^{2}+2 \alpha_{1} \beta_{1}+\beta_{1}^{2}<1$. Ng and McAleer (2004) show the importance to verify these conditions 9

The sum of $\alpha_{i}$ and $\beta_{j}$ quantifies the persistence of shocks to conditional variance, meaning that the effect of a volatility shock vanishes over time at an exponential rate. The GARCH models are short-term memory which define explicitly an intertemporal causal dependence based on a past time path. In such model, the probability of a price increasing or decreasing is a function of both the current state of the price but also the prices assumed in the previous instants.

\footnotetext{
${ }^{8}$ Nelson and Cao (1992) show that the restrictions imposed by Bollerslev (1986), i.e. the nonnegativity of all parameters in the condition variance specification, can be substantially relaxed. They derive necessary and sufficient conditions for $p \leq 2$ and sufficient conditions for $p>2$. More specifically, some of the parameters are allowed to have negative sign. Note that the Nelson and Cao (1992) conditions are implemented in econometric packages such as $\mathrm{G} @ \mathrm{RCH}$ package for Ox.

${ }^{9}$ Note the fourth moment condition is not satisfied for the $\operatorname{GARCH}(1,1)$ models estimated by Arouri et al. (2012) and Vivian and Wohar (2012)
} 


\subsection{The Integrated GARCH models}

In many high-frequency time-series applications, the conditional variance estimated using a $\operatorname{GARCH}(p, q)$ process exhibits a strong persistence that is described as follows:

$$
\sum_{i=1}^{q} \alpha_{i}+\sum_{j=1}^{p} \beta_{j} \approx 1
$$

Defining $v_{t}=\varepsilon_{t}^{2}-\sigma_{t}^{2}$, the $\operatorname{GARCH}(p, q)$ model may be rewritten as an $\operatorname{ARMA}(p, q)$ process:

$$
\begin{aligned}
& \sigma_{t}^{2}=\omega+\alpha(L) \varepsilon_{t}^{2}+\beta(L) \sigma_{t}^{2} \\
& {[1-\alpha(L)-\beta(L)] \varepsilon_{t}^{2}=\omega+[1-\beta(L)] v_{t}}
\end{aligned}
$$

Allowing for the presence of a unit root in $[1-\alpha(L)-\beta(L)]$ (the sum of $\alpha_{i}$ and $\beta_{j}$ is equal to one), Engle and Bollerslev (1986) defined the $\operatorname{IGARCH}(p, q)$ process:

$$
\begin{aligned}
(1-L) \phi(L) \varepsilon_{t}^{2} & =\omega+[1-\beta(L)] \mathrm{v}_{t} \\
\sigma_{t}^{2} & =\omega[1-B(L)]^{-1}+\left\{1-\phi(L)(1-L)[1-\beta(L)]^{-1}\right\} \varepsilon_{t}^{2}
\end{aligned}
$$

where $\phi(L)=[1-\alpha(L)-\beta(L)](1-L)^{-1}$.

The unconditional variance of an IGARCH model is not finite, implying a complete persistence of such a shock that is multiperiod forecasts of volatility will tend upwards. Recently, it has been suggested that either long memory (Mikosch and Starica, 2004) or parameter changes (Hillebrand, 2005) in the data generating process can give the impression of IGARCH model.

\subsection{The Fractionally Integrated GARCH models}

A GARCH model features an exponential decay in the autocorrelation of conditional variances. However, it has been noted that squared and absolute returns of financial assets typically have serial correlations that are slow to decay similar to those of an $\mathrm{I}(d)$ process. A shock in the volatility series seems to have very long memory and impact on future volatility over a long horizon. The IGARCH model captures this 
effect but a shock in this model impacts upon future volatility over an infinite horizon and the unconditional variance does not exist for this model. This model implies that shocks to the conditional variance persist indefinitely and this is difficult to reconcile with the persistence observed after large shocks, such as the crash of October 1987, and also with the perceived behaviour of agents who do not appear to frequently and radically alter the composition of their portfolios, as would be implied by IGARCH (Mills, 1990). So the widespread observation of the IGARCH behaviour may be an artefact of a long memory.

Baillie, Bollerslev and Mikkelsen (1996) introduce the Fractionally Integrated GARCH (FIGARCH) which encompasses the possibility of persistent but not necessarily permanent shocks to volatility. The $\operatorname{FIGARCH}(p, d, q)$ process is then defined as follows:

$$
\begin{aligned}
(1-L)^{d} \phi(L) \varepsilon_{t}^{2} & =\omega+[1-\beta(L)] v_{t} \\
\sigma_{t}^{2} & =\omega[1-\beta(L)]^{-1}+\left\{1-[1-\beta(L)]^{-1} \phi(L)(1-L)^{d}\right\} \varepsilon_{t}^{2}
\end{aligned}
$$

where $0 \leq d \leq 1, \omega>0,0 \leq \phi_{i}<1,0 \leq \beta_{i}<1 ; d$ is the fractional difference parameter, and $(1-L)^{d}$ is the fractional difference operator ${ }^{10}$ Conrad and Haag (2006) have derived necessary and sufficient conditions for the non-negativity of the conditional variance in the FIGARCH model of the order $p \leq 2$ and sufficient conditions for $p > 2 \longdiv { 1 1 }$

Interestingly, the FIGARCH$(1, d, 1)$ model nests the $\operatorname{GARCH}(1,1)$ model for $d=0$ and the IGARCH model for $d=1$. As advocated by Baillie et al. (1996), the IGARCH process may be seen as too restrictive as it implies infinite persistence of a volatility shock. Such a dynamics contradicts stylized facts (see Baillie et al., 1996; Bollerslev

\footnotetext{
${ }^{10}$ Chung (2001) underscores some drawbacks in the Baillie et al. (1996) FIGARCH model, leading to difficult interpretations of the estimated parameters. He proposes a slightly different FIGARCH process and expresses the following sufficient conditions: $0 \leq \phi_{1} \leq \beta_{1} \leq d \leq 1$ to ensure positivity of conditional variances of $\operatorname{FIGARCH}(1, d, 1)$ model. However, these conditions are not observed for all the series of interest.

${ }^{11}$ Conrad and Haag (2006) show that their conditions for the $\operatorname{FIGARCH}(1, d, 1)$ model substantially enlarge the sufficient parameter set provided by Bollerslev and Mikkelsen (1996).
} 
and Engle, 1993). By contrast, for $0<d<1$, the FIGARCH model implies a longmemory behavior and a slow rate of decay after a volatility shock. The autocorrelation of conditional variances decays at an hyperbolic, rather than an exponential (as in an IGARCH model), rate, so that the fractional differencing parameter provides important information about the pattern and speed with which shocks to volatility are propagated. In these processes, shocks to the conditional variance decay at a slow hyperbolic rate which is more strongly supported by financial data than the GARCH model. This means that the effect of a volatility shock is mean reverting but is quite persistent.

\subsection{The Hyperbolic GARCH models}

Another long-memory model of the conditional variance which generalizes the FIGARCH model is the hyperbolic GARCH (HYGARCH) model of Davidson (2004), which can be viewed as a two-component GARCH specification with one component being GARCH and the other being FIGARCH. The HYGARCH model permits the existence of second moments at more extreme amplitudes compared with the simple IGARCH and FIGARCH models. Thus, the HYGARCH model is covariance stationary while the IGARCH and FIGARCH models are not covariance stationary. The $\operatorname{HYGARCH}(p, d, q)$ model is given by:

$$
\sigma_{t}^{2}=\omega[1-\beta(L)]^{-1}+\left\{1-[1-\beta(L)]^{-1} \phi(L)(1+k)\left[(1-L)^{d}-1\right]\right\} \varepsilon_{t}^{2}
$$

where $k \geq 0$ and $d \geq 0$. The HYGARCH model nests the FIGARCH and GARCH models when $k=1$ and $k=0$, respectively. For $0<k<1$ this process is stationary, while for $k>1$ it implies that this process is non-stationary. The HYGARCH model allows to combine the desired properties of hyperbolically decaying impulse response coefficients and covariance stationary. Recently, Conrad (2010) has derived nonnegativity conditions for HYGARCH model which are necessary and sufficient for $p=1$ and sufficient for $p \geq 2.12$

\footnotetext{
${ }^{12}$ Conrad (2010) advise that these non-negativity conditions "are a first inevitable check of model validation".
} 


\subsection{Results of the persistence estimates}

In this section we compare estimates of the four volatility models (GARCH, IGARCH, FIGARCH and HYGARCH) from three ways: (1) original data; (2) original data with structural breaks identified from the modified ICSS algorithm; and (3) outlier-adjusted data. For the second approach, we introduce identified breaks into the GARCH and IGARCH models by incorporating dummy variables that take a value of one from each point of structural change of variance onwards and take a value of zero elsewhere ${ }^{13}$ Indeed, it is well known that structural changes tends to overestimate volatility persistence (Lamoureux and Lastrapes, 1990). As no restrictions are placed on the dummy effects, it is necessary to check that the variance is always positive.

The existence of the long memory assume, a priori, that returns series has constant unconditional variance. Investigating long memory with unstable unconditional variance will give deviated results. In this study, to make unconditional variance stable we follow the method proposed by Nouira et al. (2004), i.e. series are filtered as follows: $r_{t}^{*}=r_{t} / \sqrt{\hat{\sigma}_{t}^{2}}$ where $\hat{\sigma}_{t}^{2}$ is estimated over each of the intervals limited by regime-shift points of the unconditional variance.

The comparison between the volatility models is evaluated from various in-sample criteria: LogLikehood (LL), Akaike (AIC), Hannan-Quinn (HQ) and stochastic complexity (RCL) (Rissanen, 1987) criteria ${ }^{14}$ Caporin (2003) show that information criteria can clearly distinguish between long and short memory data generating processes. Mitchell and McKenzie (2003, 2008) find that the HQ and RCL criteria exhibit a clear superiority in their ability to accurately select the correct model for ARCH and GARCH processes 15

\footnotetext{
${ }^{13}$ The estimates of dummies variables are not reported to save space, but they are all significant and available from the authors upon request.

${ }^{14}$ The out-of-sample comparison is beyond the scope of this study. Future research is encouraged to address this issue.

${ }^{15}$ Mitchell and McKenzie (2008) also empirically assess the relative merits of the HQ and RCL criteria versus the Hansen and Lunde (2005) test.
} 
Tables 55 12 provide the initial estimation results for the GARCH, IGARCH, FIGARCH and HYGARCH models. The parameters of the volatility models are estimated by maximizing the log-likelihood function from the Berndt et al. (1974) (BHHH) algorithm ${ }^{16}$ For each Table, the best model are given in bold face, owing to the higher value of the LL, and the lower values of the AIC, HQ and RCL. The residuals tests are also reported to check if the chosen volatility model is the most appropriated. Note that the estimation of the $\operatorname{GARCH}(1,1), \operatorname{FIGARCH}(1, d, 1)$ and HYGARCH$(1, d, 1)$ models is not reported for some return series because the regularity and non-negativity conditions are not observed. Further, the estimated HYGARCH models are not discussed because the parameter $k$ is never significant.

Original data. The IGARCH process captures the best temporal pattern of volatility for the three return series (Tables 5,8 and 11 , respectively). This model outperforms FIGARCH model for Brent returns, implying that the shocks to the conditional variance persist indefinitely (Table 5). For the OPEC and WTI returns, the GARCH, FIGARCH and HYGARCH models do not satisfy the regularity and non-negativity conditions, suggesting that structural breaks and/or outliers can bias these conditions.

Original data with dummies. Tables 6 and 9 show that the Brent and OPEC return series are better modelled by a FIGARCH model exhibiting thus long memory. This result confirm those of Lamoureux and Lastrapes (1990), Mikosch and Starica (2004) and Hillebrand (2005), among others, showing that structural breaks in volatility can bias the estimated persistence of volatility. The parameter $d$, i.e. the degree of fractional integration, is highly significantly different both from 0 and 1 , rejecting the validity of both the GARCH and the IGARCH specifications $\sqrt[17]{7}$ This implies that

\footnotetext{
${ }^{16}$ To estimate and forecast these indexes, we use G@RCH 6.0 for Ox (Laurent and Peters, 2001), a package dedicated to the estimation and the forecasting of GARCH models and many of their extensions.

${ }^{17}$ We test the persistence of the volatility model using the Wald statistics, that is $\alpha+\beta=1$ for GARCH models and $d=0$ and $d=1$ for FIGARCH models. Results are not reported to save space but they are available from the authors upon request.
} 
the process is said to exhibit long memory, a characteristic in financial time series in which the dependence between distant observations is not negligible. For the Brent returns (Table 6), the degree of fractional integration is smaller for the filtered series $(d=0.578)$ than for the original data set $(d=0.653)$. This supports that long-range dependence may be due to the presence of structural.

Outlier-adjusted data. For the Brent return series, the short-memory (GARCH model) appears to be the most relevant to fit the data (Table 7). Consequently, the effect of a volatility shock vanishes over time at an exponential rate. This finding implies that the presence of outlier bias the estimation of the volatility persistence. However, the short-term persistence falls slightly $(\alpha+\beta=0.99)$. Tables 10 and 12 display that the better specification of OPEC and WTI return series is the IGARCH model. Nevertheless, the value of $\alpha$ decreases and the value of $\beta$ increase when the data are cleaned of outliers. This result may be explained by the fact that identified outliers are consecutive (Carnero et al., 2001). For these return series, the GARCH, FIGARCH and HYGARCH models do not satisfy the regularity and non-negativity conditions, suggesting that outliers can bias these conditions. This finding confirms that of $\mathrm{Ng}$ and McAleer (2004), showing that the additive outliers can affect the moment conditions of GARCH models 18

\section{Conclusion}

This study assessed the impact of structural changes and outliers on volatility persistence of three crude oil markets (Brent, OPEC and WTI). Given the importance of measuring the degree to which past volatilities determine and explain the current volatility, a careful investigation of various possible explanations on this fact should

\footnotetext{
${ }^{18}$ Haldrup and Nielsen (2007) show that an additive outlier may substantially bias the differencing parameter estimate in ARFIMA processes. Carnero et al. (2007, 2012) and Ng and McAleer (2004) who show that the QML estimators can be severally affected by additive outliers, i.e. both the GARCH parameters can be overestimated or underestimated.
} 
be carried out, with emphasis on the understanding of the statistical subtleties of this issue.

Firstly, we identified the time points at which structural changes occurred using the modified ICSS test developed by Sansó et al. (2004) and then incorporated this information into the volatility modeling. Our results indicated that the degree of persistence of volatility was reduced by incorporating the variance changes into the volatility model. Secondly, we identified outliers using intervention analysis and conditional heteroscedasticity model. These large shocks can be associated with particular event patterns, such as the invasion of Kuwait by Iraq, the Operation Desert Storm, the Operation Desert Fox, and the Global Financial Crisis as well as OPEC announcements on production reduction or US announcements on crude inventories. We found that the crude oil markets are more affected by outliers and patches of outliers than by variance changes. We also showed that outliers can bias the estimation of the persistence of the volatility. Taking into account outliers on the volatility modelling process improve the understanding of volatility in crude oil markets.

Further research would be to compare the forecasting accuracy of volatility models that take or not into account the presence of structural changes and outliers, using out-of-sample criteria. 


\section{References}

[1] Andreou E. and Ghysels E. (2002). Detecting multiple breaks in financial market volatility dynamics. Journal of Applied Econometrics, 17, 579-600.

[2] Aragó V. and Fernandez-Izquierdo A. (2003). GARCH models with changes in variance: An approximation to risk measurements. Journal of Asset Management, 4, 277-287.

[3] Arouri M., Lahiani A., Lévy A. and Nguyen D.K. (2012). Forecasting the conditional volatility of oil spot and futures prices with structural breaks and long memory models. Energy Economics, 34, 283-293.

[4] Askari H. and Khrichene N. (2008). Oil price dynamics (2002-2006). Energy Economics, 30, 2134-2153.

[5] Bacmann J.F. and Dubois M. (2002). Volatility in emerging stock markets revisited. European Financial Management Association, London Meeting, 26-29 June 2002.

[6] Bali R. and Guirguis H. (2007). Extreme observations and non-normality in $\mathrm{ARCH}$ and GARCH. International Review of Economics and Finance, 16, 332346.

[7] Berndt, E.R., Hall, B.H., Hall, R.E., Hausman, J.A. (1974). Estimation and inference in nonlinear structural models. Annals of Economic and Social Measurement 3, 653-665.

[8] Bollerslev T. (1986). Generalized Autoregressive Conditional Heteroskedasticity. Journal of Econometrics, 31, 307-327.

[9] Bollerslev T. and Mikkelsen H.O. (1996). Modelling and pricing long memory in stock market volatility. Journal of Econometrics, 73, 151-184. 
[10] Box G.E.P. and Tiao G.C. (1975). Intervention analysis with applications to economic and environmental problems. Journal of the American Statistical Association, 70, 70-79.

[11] Caporin M. (2003). Identification of long memory in GARCH models. Statistical Methods and Applications, 12, 133-151.

[12] Carnero M.A., Peña D. and Ruiz E. (2001). Outliers and conditional autoregressive heteroskedasticity in time series. Revista Estadistica, 53, 143-213.

[13] Carnero M.A., Peña D. and Ruiz E. (2007). Effects of outliers on the identification and estimation of the GARCH models. Journal of Time Series Analysis, 28, 471-497.

[14] Carnero M.A., Peña D. and Ruiz E. (2012). Estimating GARCH volatility in the presence of outliers. Economics Letters, 114, 86-90.

[15] Charles A. and Darné O. (2005). Outliers and GARCH models in financial data. Economics Letters, 86, 347-352.

[16] Chen C. and Liu L.M. (1993). Joint estimation of model parameters and outlier effects in time series. Journal of the American Statistical Association, 88, 284297.

[17] Conrad C. (2010). Non-negativity conditions for the hyperbolic GARCH model. Journal of Econometrics, 157, 441-457.

[18] Conrad C. and Haag B.R. (2006). Inequality constraints in the fractionally integrated GARCH model. Journal of Financial Econometrics, 4, 413-449.

[19] Chung C-F. (2001). Estimating the fractionally integrated GARCH model. Discussion Paper, National Taiwan University.

[20] Davidson J. (2004). Moment and memory properties of linear conditional heteroscedasticity models, and a new model. Journal of Business and Economic Statistics, 22, 16-19. 
[21] Demirer R. and Kutan A.M. (2010). The behavior of crude oil spot and futures prices around OPEC and SPR announcements: An event study perspective. Energy Economics, 32, 1467-1476.

[22] Ding Z. and Granger C.W.J. (1996). Modeling volatility persistence of speculative returns: A new approach. Journa of Econometrics, 73, 185-215.

[23] Doornik J.A. and Ooms M. (2005). Outlier detection in GARCH models. Discussion Paper No 2005-092/4, Tinbergen Institute.

[24] Engle R.F. (1982). Autoregressive conditional heteroskedasticity with estimates of the variance of United Kingdom inflation. Econometrica, 50, 987-1007.

[25] Engle R.F. and Bollerslev T. (1986). Modelling the persistence of conditional variances. Econometric Reviews, 5, 1-50.

[26] Ewing B.T. and Malik F. (2010). Estimating volatility persistence in oil prices under structural breaks. The Financial Review, 45, 1011-1023.

[27] Fernandez V. (2006). The impact of major global events on volatility shifts: Evidence from the Asian crisis and 9/11. Economic Systems, 30, 79-97.

[28] Fong W.M. and See K.H. (2002). A Markov switching model of the conditional volatility of crude oil futures prices. Energy Economics, 24, 71-95.

[29] Fong W.M. and See K.H. (2003). Basis variations and regime shifts in the oil futures market. European Journal of Finance, 9, 499-513.

[30] Franses P.H. and Ghijsels H. (1999). Additive outliers, GARCH and forecasting volatility. International Journal of Forecasting, 15, 1-9.

[31] Franses P.H. and van Dijk D. (2000). Nonlinear Time Series Models in Empirical Finance. Cambridge University Press, Cambridge.

[32] Haldrup N. and Nielsen M.O. (2007). Estimation of fractional integration in the presence of data noise. Computational Statistics and Data Analysis, 51, 31003114 . 
[33] Hammoumdeh S. and Li H. (2008). Sudden changes in volatility in emerging markets: The case of Gulf Arab stocks markets. International Review of Financial Analysis, 17, 47-63.

[34] Hansen P. and Lunde A. (2005). A forecast comparison of volatility models: Does anything beat a GARCH(1,1). Journal of Applied Econometrics, 20, 873-89.

[35] Hillebrand E. (2005). Neglecting parameter changes in GARCH models. Journal of Econometrics 129, 121-138.

[36] Horsnell P. and Mabro R. (1993). Oils Markets and Prices: The Brent Market and the Formation of World Oil Prices. Oxford University Press, Oxford.

[37] Hotta L.K. and Tsay R.S. (1999). Outliers in GARCH processes. Manuscript, University of Chicago.

[38] Hyndman K. (2008). Disagreement in bargaining: An empirical analysis of OPEC. International Journal of Industrial Organization, 26, 811-828.

[39] Inclán C. and Tiao G.C. (1994). Use of cumulative sums of squares for retrospective detection of changes of variance. Journal of the American Statistical Association, 89, 913-923.

[40] Kang S.H., Cheong C. and Yoon S-M. (2011). Structural changes and volatility transmission in crude oil markets. Physica A, 390, 4317-4324.

[41] Kokoszka P. and Leipus R. (2000). Change-point estimation in ARCH models. Bernoulli, 6, 513-539.

[42] Krämer W. and Azamo B.T. (2007). Structural change and estimated persistence in the GARCH(1,1)-model. Economics Letters, 97, 17-23.

[43] Lamoureux C.G. and Lastrapes W.D. (1990). Persistence in variance, structural change and the GARCH model. Journal of Business and Economic Statistics, 8, 225-234. 
[44] Larsson K. and Nossman M. (2011). Jumps and stochastic volatility in oil prices: Time series evidence. Energy Economics, 33, 504-514.

[45] Laurent S. and Peters J.P. (2002). G@ @rch 2.2: An Ox package for estimating and forecasting various ARCH models. Journal of Economic Surveys 16, 447-485.

[46] Lin S.X. and Tamvakis M. (2010). OPEC announcements and their effects on crude oil prices. Energy Policy, 38, 1010-1016.

[47] Ling S. and McAleer M. (2002a). Necessary and sufficient moment conditions for the $\operatorname{GARCH}(r, s)$ and Asymmetric Power $\operatorname{GARCH}(r, s)$ models. Econometric Theory, 18, 722-729.

[48] Ling S. and McAleer M. (2002b). Stationarity and the existence of moments of a family of GARCH processes. Journal of Econometrics, 106, 109-117.

[49] McKenzie M.D. (1997). ARCH modelling of Australian bilateral exchange rate data. Applied Economics, 7, 147-164.

[50] Mitchell H. and McKenzie M.D. (2003). GARCH model selection criteria. Quantitative Finance, 3, 262-84.

[51] Mitchell H. and McKenzie M.D. (2008). A comparison of alternative techniques for selecting an optimum ARCH model. Journal of Statistical Computation and Simulation, 78, 51-67.

[52] Mikosch T. and Starica C. (2004). Nonstationarities in financial time series, the long-range dependence, and the IGARCH effects. Review of Economics and Statistics, 86, 378-390.

[53] Nelson D.B. (1990a). ARCH models as diffusion approximations. Journal of Econometrics, 45, 7-38.

[54] Nelson D.B. (1990b). Stationarity and persistence in the GARCH(1,1) model. Journal of Econometrics 45, 7-38. 
[55] Nelson D.B. and Cao C.Q. (1992). Inequality constraints in the univariate GARCH model. Journal of Business and Economic Statistics, 10, 229-235.

[56] Ng H.G. and McAleer M. (2004). Recursive modelling of symmetric and asymmetric volatility in the presence of extreme observations. International Journal of Forecasting, 20, 115-129.

[57] Nouira L., Ahamada I., Jouni J. and Nurbel A. (2004). Long-memory and shifts in the unconditional variance in the exchange rate euro/US dollar returns. Applied Economics Letters, 11, 591-594.

[58] Pindyck R.S. (1999). The long-run evolution of energy prices. Energy Journal, $20,1-27$.

[59] Rissanen J.J. (1987). Stochastic complexity. Journal of the Royal Statistical Society, Series B, 49, 223-239.

[60] Rodrigues P.M.M. and Rubia A. (2011). The effects of additive outliers and measurement errors when testing for structural breaks in variance. Oxford Bulletin of Economics and Statistics, 73, 449-468.

[61] Sakata S. and White H. (1998). High breakdown point conditional dispersion estimation with application to S\&P 500 daily returns volatility. Econometrica, $66,529-567$.

[62] Sansó A., Aragó V. and Carrion-i-Silvestre J. (2004). Testing for changes in the unconditional variance of financial time series. Revista de Economía Financiera, $4,32-53$.

[63] Taylor S.J. (1986). Forecasting the volatility of currency exchange rates. International Journal of Forecasting, 3, 159-170.

[64] van Dijk D., Franses P.H. and Lucas A. (1999). Testing for ARCH in the presence of additive outliers. Journal of Applied Econometrics, 14, 539-562. 
[65] Verhoeven P., and McAleer M. (2000). Modelling outliers and extreme observations for ARMA-GARCH processes. Working paper, University of Western Australia.

[66] Vivian A. and Wohar M.E. (2012). Commodity volatility breaks. Journal of International Financial Markets, Institutions and Money, 22, 395-422.

[67] Vo M.T. (2009). Regime-switching stochastic volatility: Evidence from the crude oil market. Energy Economics, 31, 779-788.

[68] Wei Y., Wang Y. and Huang D. (2010). Forecasting crude oil market volatility: Further evidence using GARCH-class models. Energy Economics, 32, 14771484.

[69] Wilson B., Aggarwal R. and Inclán C. (1996). Detecting volatility changes across the oil sector. Journal of Futures Markets, 16, 313-320.

[70] Zhang X. and King M. (2005). Influence in generalized autoregressive conditional heteroscedasticity processes. Journal of Business and Economic Statistics, $23,118-129$. 
Figure 1: Daily returns of Brent, OPEC and WTI crude oil markets.
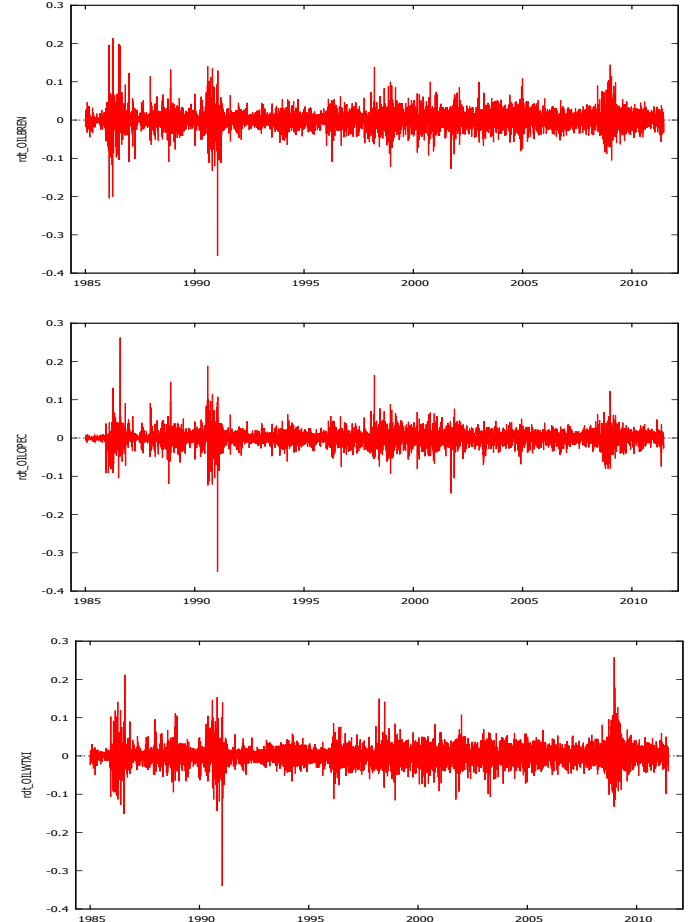
Table 1: Summary statistics of crude oil markets.

\begin{tabular}{lccccccc}
\hline \hline Series & Mean (\%) & St. dev. & Min. & Max. & Skewness & Excess Kurtosis & LM(10) \\
\hline Non-adjusted data & & & & & & & \\
Brent & 0.0501 & 0.024 & -0.355 & 0.214 & $-0.163^{*}$ & $14.7^{*}$ & $2590.9^{*}$ \\
OPEC & 0.0400 & 0.020 & -0.349 & 0.263 & $-0.321^{*}$ & $24.6^{*}$ & $2590.9^{*}$ \\
WTI & 0.0485 & 0.024 & -0.340 & 0.258 & $-0.062^{*}$ & $12.3^{*}$ & $2590.9^{*}$ \\
\hline Adjusted data & & & & & & & \\
Brent & 0.0351 & 0.018 & -0.081 & 0.083 & $-0.185^{*}$ & $2.19^{*}$ & $2590.9^{*}$ \\
OPEC & 0.0468 & 0.022 & -0.098 & 0.104 & -0.001 & $2.23^{*}$ & $2590.9^{*}$ \\
WTI & 0.0420 & 0.022 & -0.104 & 0.106 & $-0.078^{*}$ & $2.31^{*}$ & $2590.9^{*}$ \\
\hline \hline
\end{tabular}

Notes: ${ }^{* *}$ mean significant at $5 \%$ level. 
Table 2: Outliers in volatility of crude oil markets.

\begin{tabular}{|c|c|c|}
\hline Date of outliers & Markets & Events \\
\hline $12 / 10 / 1985$ & OPEC, WTI & OPEC decision to expand its share of world oil markets \\
\hline 02/03/1986 & Brent & $\begin{array}{l}\text { Doubt on OPEC to stabilize oil prices } \\
\text { after the failure of an agreement on production }\end{array}$ \\
\hline 03/24/1986 & Brent & OPEC meeting without an agreement on production ceilings \\
\hline 03/31/1986 & Brent & $\begin{array}{l}\text { Prediction of further decline of oil prices by the United Arab } \\
\text { Emirates' oil minister }\end{array}$ \\
\hline 04/01/1986 & Brent & $\begin{array}{l}\text { Plan by Vice President George Bush to discuss oil-price stability } \\
\text { with Saudi Arabian officials }\end{array}$ \\
\hline 04/07/1986 & Brent, OPEC, WTI & $\begin{array}{l}\text { The Reagan administration is reconsidering its proposal to stop } \\
\text { buying oil for the nation's Strategic Petroleum Reserve }\end{array}$ \\
\hline 04/08/1986 & OPEC, WTI & Soviet Union raises exports to West \\
\hline 05/23/1986 & WTI & Growing tensions in the Mideast \\
\hline 07/08/1986 & OPEC & OPEC report on supply buildup \\
\hline 07/16/1986 & Brent & $\begin{array}{l}\text { Statement by Saudi Arabian King Fahd urging stability } \\
\text { in the world oil markets }\end{array}$ \\
\hline 07/22/1986 & WTI & Doubt on OPEC actions to curb runaway production \\
\hline 08/04/1986 & Brent, OPEC, WTI & OPEC report on possible reduction of production \\
\hline 08/05/1986 & Brent, OPEC & Boycott Libyan Oil \\
\hline 10/30/1986 & OPEC & $\begin{array}{l}\text { Saudi Arabian oil minister called for an emergency } \\
\text { price-level OPEC meeting }\end{array}$ \\
\hline 01/01/1987 & Brent & OPEC agreement on production \\
\hline $12 / 22 / 1987$ & Brent, OPEC & OPEC report on cutting back production \\
\hline $10 / 24 / 1988$ & Brent, OPEC, WTI & Leading OPEC oil ministers pledge to limit production \\
\hline $11 / 25 / 1988$ & Brent, OPEC, WTI & Possible agreement between Iran and Iraq on oil quotas \\
\hline 08/02/1990 & Brent, OPEC, WTI & Invasion of Kuwait by Iraq \\
\hline 08/06/1990 & Brent, OPEC, WTI & Economic sanctions against Iraq by the UN Security Council \\
\hline 08/08/1990 & OPEC & President Saddam Hussein proclaims annexation of Kuwait \\
\hline 09/24/1990 & Brent, OPEC, WTI & $\begin{array}{l}\text { Iraq invades the French and Dutch missions in Kuwait } \\
\text { Threat of Saddam Hussein to attack Israel } \\
\text { and to destroy the oil wells }\end{array}$ \\
\hline $11 / 30 / 1990$ & Brent, OPEC, WTI & Diplomatic initiative by President George Bush \\
\hline
\end{tabular}


Table 3: Outliers in volatility of crude oil markets.

\begin{tabular}{|c|c|c|}
\hline Date of outliers & Markets & Events \\
\hline 01/17/1991 & Brent, OPEC, WTI & Beginning of Operation Desert Storm \\
\hline \multirow[t]{3}{*}{ 01/18/1991 } & OPEC & Danger of Iraqi offensive against Saudi Arabian \\
\hline & & Iraqi Scud missiles land in Israel \\
\hline & & oil infrastructure is discarded \\
\hline \multirow[t]{2}{*}{ 01/22/1991 } & Brent, OPEC, WTI & Destruction by Iraq of Kuwaiti oil installations \\
\hline & & Iraqi missile attacks on Saudi Arabia \\
\hline $02 / 15 / 1991$ & Brent, OPEC & Iraki proposal to withdraw from Kuwait is failed \\
\hline 03/23/1998 & Brent, OPEC, WTI & OPEC agreement to reduce production \\
\hline 06/22/1998 & WTI & Further reductions in OPEC production \\
\hline $12 / 16 / 1998$ & Brent, OPEC, WTI & Beginning of Operation Desert Fox \\
\hline $12 / 17 / 1998$ & Brent, OPEC, WTI & Iraqi oil installations are not aimed by American missiles \\
\hline \multirow[t]{2}{*}{$10 / 12 / 2000$} & Brent & Threat of an Arab-Israeli war \\
\hline & & Terrorist attack on an American warship in Yemen \\
\hline $09 / 24 / 2001$ & Brent, OPEC, WTI & Fear of a sharp drop in demand \\
\hline \multirow[t]{2}{*}{$11 / 15 / 2001$} & OPEC & OPEC decide to reduce its production as long as \\
\hline & & non-OPEC members also reduce their production \\
\hline $12 / 28 / 2001$ & WTI & OPEC decides to reduce its production \\
\hline \multirow[t]{2}{*}{$01 / 03 / 2003$} & Brent & Decline in US crude inventories and \\
\hline & & oil industry strike in Venezuela \\
\hline $04 / 23 / 2003$ & WTI & Unexpected rise in US crude inventories \\
\hline $12 / 30 / 2004$ & Brent & Terrorist attack in Saudi Arabia \\
\hline $12 / 22 / 2008$ & WTI & Recovery of storage capacity at Cushing \\
\hline $12 / 29 / 2008$ & WTI & Israeli attacks on Gaza \\
\hline $01 / 02 / 2009$ & OPEC, WTI & Possible extraordinary OPEC meeting on oil prices in February \\
\hline $01 / 05 / 2009$ & Brent, OPEC & Spike in oil consumption due to cold, and Russian-Ukrainian dispute \\
\hline 01/07/2009 & WTI & Rise in US crude inventories \\
\hline $01 / 21 / 2009$ & Brent, WTI & Possibility of further production cuts at the next OPEC meeting \\
\hline \multirow[t]{2}{*}{$01 / 27 / 2009$} & Brent & OPEC decides to keep strict production quotas whereas investors \\
\hline & & estimate that demand could remain higher than supply \\
\hline $02 / 13 / 2009$ & WTI & High US crude inventories \\
\hline $02 / 19 / 2009$ & WTI & Surprise drop in US crude inventories \\
\hline
\end{tabular}


Table 4: Sudden changes in volatility

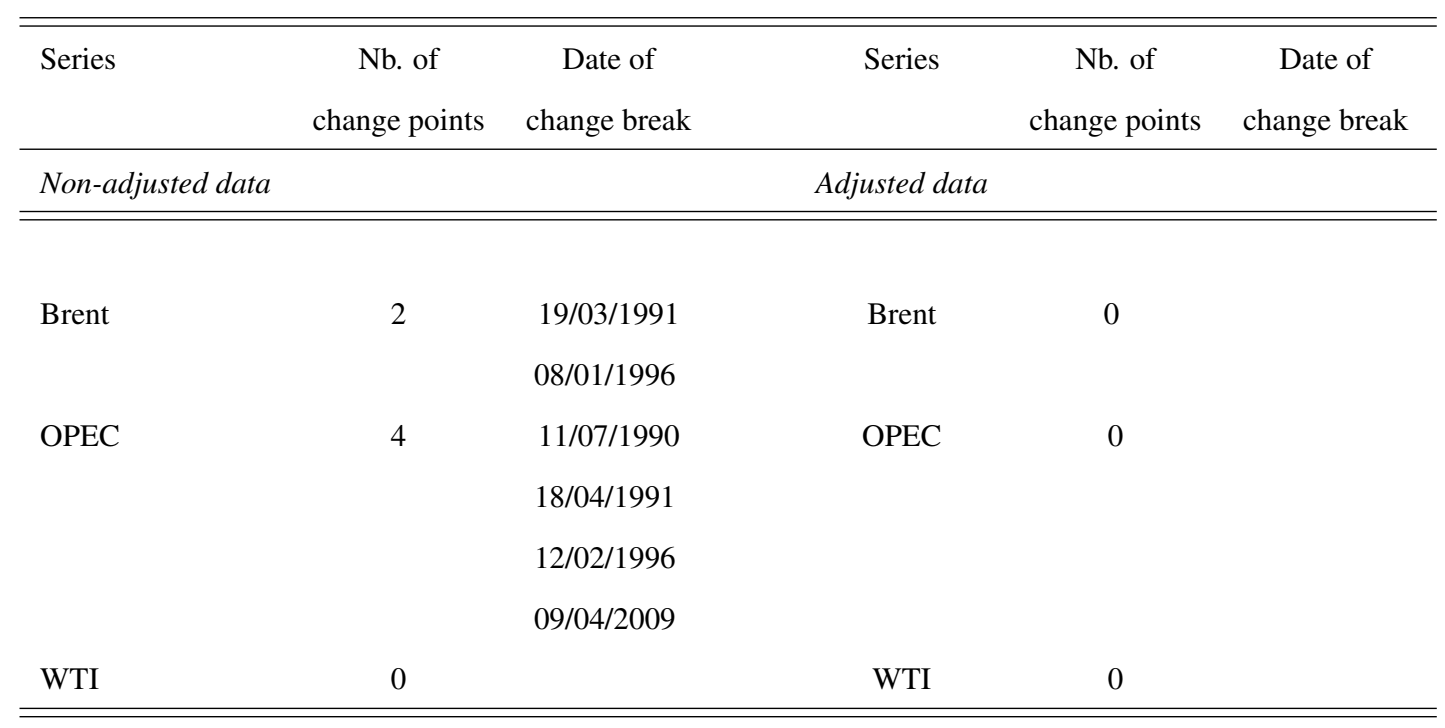


Table 5: Estimates of volatility models

\begin{tabular}{|c|c|c|c|c|}
\hline & $\operatorname{GARCH}(1,1)^{a}$ & IGARCH & FIGARCH & HYGARCH \\
\hline \multicolumn{5}{|c|}{ Brent: original data } \\
\hline \multicolumn{5}{|c|}{ Parameters } \\
\hline$\alpha$ & $n c$ & $0.081735^{* *}$ & & \\
\hline$\beta$ & $n c$ & 0.918265 & $0.724955^{* *}$ & $0.727120^{* *}$ \\
\hline$\alpha+\beta$ & $n c$ & 1 & & \\
\hline$\phi$ & & & $0.157407^{* *}$ & $0.155730^{* *}$ \\
\hline$d$ & & & $0.653362^{* *}$ & $0.658483^{* *}$ \\
\hline$k$ & & & & -0.002387 \\
\hline \multicolumn{5}{|c|}{ In-sample criteria ${ }^{b}$} \\
\hline LL & $n c$ & -14856.297 & -14857.962 & $n c$ \\
\hline AIC & $n c$ & 4.305171 & 4.306233 & $n c$ \\
\hline HQ & $n c$ & 4.306561 & 4.307941 & $n c$ \\
\hline $\mathrm{RCL}$ & $n c$ & 4.305752 & 4.306976 & $n c$ \\
\hline \multicolumn{5}{|c|}{ Residuals tests $^{c}$} \\
\hline$Q(10)$ & $n c$ & $14.9692^{* *}$ & $14.8722^{* *}$ & $n c$ \\
\hline$Q^{2}(10)$ & $n c$ & $8.81817^{* *}$ & $9.51307^{* *}$ & $n c$ \\
\hline$L M(10)$ & $n c$ & $0.87572^{* *}$ & $0.93307^{* *}$ & $n c$ \\
\hline
\end{tabular}

Notes: $n c$ means "not computed". ${ }^{a}$ The condition for existence of the fourth moment of the GARCH is not observed (Ling and McAleer, 2001). ${ }^{b}$ LL is the log-likehood value, AIC, HQ and RCL correspond to the Akaike, HannanQuinn and Rissanen criteria, respectively. ${ }^{c} Q(10)$ and $Q^{2}(10)$ are respectively the Box Pierce statistics at lag 10 of the standardized and squared standardized residuals. They are asymptotically distributed as $\chi^{2}(k)$ where $k$ is the lag length. $\mathrm{LM}(10)$ is the ARCH LM test at lag 10. It is distributed as $\chi^{2}(q)$ where $q$ is the lag length. ${ }^{* *}$ indicates that the null hypothesis is rejected at $5 \%$ level. 
Table 6: Estimates of volatility models

\begin{tabular}{|c|c|c|c|c|}
\hline & $\operatorname{GARCH}(1,1)$ & IGARCH & FIGARCH & HYGARCH \\
\hline \multicolumn{5}{|c|}{ Brent: original data with break } \\
\hline \multicolumn{5}{|c|}{ Parameters } \\
\hline$\alpha$ & $0.079796^{* *}$ & $0.084822^{* *}$ & & \\
\hline$\beta$ & $0.911640^{* *}$ & 0.915178 & $0.661326^{* *}$ & $0.672528^{* *}$ \\
\hline$\alpha+\beta$ & 0.99144 & 1 & & \\
\hline$\phi$ & & & $0.168242^{* *}$ & $0.157505^{* *}$ \\
\hline$d$ & & & $0.577992^{* *}$ & $0.613511^{* *}$ \\
\hline$k$ & & & & -0.027338 \\
\hline \multicolumn{5}{|c|}{ In-sample criteria ${ }^{b}$} \\
\hline LL & -14848.252 & -14852.361 & -14845.737 & $n c$ \\
\hline AIC & 4.303999 & 4.304899 & 4.303560 & $n c$ \\
\hline HQ & 4.310935 & 4.310844 & 4.306293 & $n c$ \\
\hline $\mathrm{RCL}$ & 4.303421 & 4.304249 & 4.303061 & $n c$ \\
\hline \multicolumn{5}{|c|}{ Residuals tests ${ }^{c}$} \\
\hline$Q(10)$ & $14.8418^{* *}$ & $14.9046^{* *}$ & $14.6965^{* *}$ & $n c$ \\
\hline$Q^{2}(10)$ & $9.11291^{* *}$ & $8.94417^{* *}$ & $8.30482^{* *}$ & $n c$ \\
\hline $\operatorname{LM}(10)$ & $0.90739^{* *}$ & $0.89195^{* *}$ & $0.82408^{* *}$ & $n c$ \\
\hline
\end{tabular}

Notes: $n c$ means "not computed". The GARCH, IGARCH and FIGARCH processes are estimated with dummies variable to take into account the variance changes detected with the modified ICSS test. ${ }^{b}$ LL is the log-likehood value, AIC, HQ and RCL correspond to the Akaike, Hannan-Quinn and Rissanen criteria, respectively. ${ }^{c} Q(10)$ and $Q^{2}(10)$ are respectively the Box Pierce statistics at lag 10 of the standardized and squared standardized residuals. They are asymptotically distributed as $\chi^{2}(k)$ where $k$ is the lag length. $\operatorname{LM}(10)$ is the ARCH LM test at lag 10. It is distributed as $\chi^{2}(q)$ where $q$ is the lag length. ${ }^{* *}$ indicates that the null hypothesis is rejected at $5 \%$ level. 
Table 7: Estimates of volatility models

\begin{tabular}{|c|c|c|c|c|}
\hline & $\operatorname{GARCH}(1,1)$ & IGARCH & FIGARCH & HYGARCH \\
\hline \multicolumn{5}{|c|}{ Brent: outlier-corrected data } \\
\hline \multicolumn{5}{|c|}{ Parameters } \\
\hline$\alpha$ & $0.056744^{*}$ & $0.060541^{*}$ & & \\
\hline$\beta$ & $0.937822^{*}$ & 0.939459 & $0.664473^{* *}$ & $0.657221^{* *}$ \\
\hline$\alpha+\beta$ & 0.99457 & 1 & & \\
\hline$\phi$ & & & $0.224818^{* *}$ & $0.228448^{* *}$ \\
\hline$d$ & & & $0.502948^{* *}$ & $0.488456^{* *}$ \\
\hline$k$ & & & & 0.007449 \\
\hline \multicolumn{5}{|c|}{ In-sample criteria ${ }^{2}$} \\
\hline LL & -14534.534 & -14538.240 & -14550.365 & $n c$ \\
\hline AIC & 4.212237 & 4.213020 & 4.217113 & $n c$ \\
\hline HQ & 4.215993 & 4.216200 & 4.218821 & $n c$ \\
\hline RCL & 4.212528 & 4.213239 & 4.217483 & $n c$ \\
\hline \multicolumn{5}{|c|}{ Residuals tests ${ }^{3}$} \\
\hline$Q(10)$ & $16.8329^{* *}$ & $16.7837^{* * *}$ & $17.0103^{* *}$ & $n c$ \\
\hline$Q^{2}(10)$ & $11.6283^{*}$ & $11.8861^{*}$ & $9.41011^{*}$ & $n c$ \\
\hline $\operatorname{LM}(10)$ & $1.1200^{*}$ & $1.1480^{*}$ & $0.91929^{*}$ & $n c$ \\
\hline
\end{tabular}

Notes: $n c$ means "not computed". ${ }^{b}$ LL is the log-likehood value, AIC, HQ and RCL correspond to the Akaike, Hannan-Quinn and Rissanen criteria, respectively. ${ }^{c} Q(10)$ and $Q^{2}(10)$ are respectively the Box Pierce statistics at lag 10 of the standardized and squared standardized residuals. They are asymptotically distributed as $\chi^{2}(k)$ where $k$ is the lag length. $\mathrm{LM}(10)$ is the ARCH LM test at lag 10. It is distributed as $\chi^{2}(q)$ where $q$ is the lag length. ${ }^{* *}$ indicates that the null hypothesis is rejected at $5 \%$ level. 
Table 8: Estimates of volatility models

\begin{tabular}{|c|c|c|c|c|}
\hline & $\operatorname{GARCH}(1,1)^{a}$ & IGARCH & FIGARCH $^{d}$ & $\mathrm{HYGARCH}^{e}$ \\
\hline \multicolumn{5}{|c|}{ OPEC: original data } \\
\hline \multicolumn{5}{|c|}{ Parameters } \\
\hline$\alpha$ & $n c$ & $0.110099^{* *}$ & & \\
\hline$\beta$ & $n c$ & 0.889901 & $n c$ & $n c$ \\
\hline$\alpha+\beta$ & $n c$ & 1 & & \\
\hline$\phi$ & & & $n c$ & $n c$ \\
\hline$d$ & & & $n c$ & $n c$ \\
\hline$k$ & & & & $n c$ \\
\hline \multicolumn{5}{|c|}{ In-sample criteria ${ }^{b}$} \\
\hline LL & $n c$ & -13264.773 & $n c$ & $n c$ \\
\hline AIC & $n c$ & 3.844060 & $n c$ & $n c$ \\
\hline HQ & $n c$ & 3.847033 & $n c$ & $n c$ \\
\hline $\mathrm{RCL}$ & $n c$ & 3.844278 & $n c$ & $n c$ \\
\hline \multicolumn{5}{|c|}{ Residuals tests ${ }^{c}$} \\
\hline$Q(10)$ & $n c$ & $16.6389^{* *}$ & $n c$ & $n c$ \\
\hline$Q^{2}(10)$ & $n c$ & $17.9963^{* *}$ & $n c$ & $n c$ \\
\hline$L M(10)$ & $n c$ & $2.1914^{* *}$ & $n c$ & $n c$ \\
\hline
\end{tabular}

Notes: $n c$ means "not computed". ${ }^{a}$ The condition for existence of the fourth moment of the GARCH is not observed (Ling and McAleer, 2001). ${ }^{d}$ Positivity constraints of the FIGARCH specification are not valid (Conrad and Haag, 2006). ${ }^{e}$ Positivity constraints of the HYGARCH specification are not valid (Conrad, 2010). ${ }^{b}$ LL is the log-likehood value, AIC, HQ and RCL correspond to the Akaike, Hannan-Quinn and Rissanen criteria, respectively. ${ }^{c} Q(10)$ and $Q^{2}(10)$ are respectively the Box Pierce statistics at lag 10 of the standardized and squared standardized residuals. They are asymptotically distributed as $\chi^{2}(k)$ where $k$ is the lag length. $\operatorname{LM}(10)$ is the ARCH LM test at lag 10. It is distributed as $\chi^{2}(q)$ where $q$ is the lag length. ${ }^{* *}$ indicates that the null hypothesis is rejected at $5 \%$ level. 
Table 9: Estimates of volatility models

\begin{tabular}{|c|c|c|c|c|}
\hline & $\operatorname{GARCH}(1,1)$ & IGARCH & FIGARCH & HYGARCH \\
\hline \multicolumn{5}{|c|}{ OPEC: original data with break } \\
\hline \multicolumn{5}{|c|}{ Parameters } \\
\hline$\alpha$ & $0.132652^{*}$ & $0.132893^{*}$ & & \\
\hline$\beta$ & $0.867031^{*}$ & 0.867107 & $0.626949^{*}$ & $0.620167^{*}$ \\
\hline$\alpha+\beta$ & 0.99968 & 1 & & \\
\hline$\phi$ & & & $0.109327^{* *}$ & $0.108868^{* *}$ \\
\hline$d$ & & & $0.675902^{*}$ & $0.674327^{*}$ \\
\hline$k$ & & & & -0.014240 \\
\hline \multicolumn{5}{|c|}{ In-sample criteria ${ }^{b}$} \\
\hline LL & -13225.816 & -13225.819 & -13212.8 & $n c$ \\
\hline AIC & 3.834511 & 3.834223 & 3.831021 & $n c$ \\
\hline HQ & 3.843429 & 3.842149 & 3.834437 & $n c$ \\
\hline $\mathrm{RCL}$ & 3.833354 & 3.832992 & 3.829952 & $n c$ \\
\hline \multicolumn{5}{|c|}{ Residuals tests ${ }^{c}$} \\
\hline$Q(10)$ & $16.8265^{* *}$ & $16.7989^{* *}$ & $194.222^{*}$ & $n c$ \\
\hline$Q^{2}(10)$ & $17.7919^{* *}$ & $17.7849^{* *}$ & $18.1988^{*}$ & $n c$ \\
\hline$L M(10)$ & $1.7921^{* *}$ & $1.7908^{* *}$ & $1.7706^{* *}$ & $n c$ \\
\hline
\end{tabular}

Notes: $n c$ means "not computed". The GARCH, IGARCH and FIGARCH processes are estimated with dummies variable to take into account the variance changes detected with the modified ICSS test. ${ }^{b}$ LL is the log-likehood value, AIC, HQ and RCL correspond to the Akaike, Hannan-Quinn and Rissanen criteria, respectively. ${ }^{c} Q(10)$ and $Q^{2}(10)$ are respectively the Box Pierce statistics at lag 10 of the standardized and squared standardized residuals. They are asymptotically distributed as $\chi^{2}(k)$ where $k$ is the lag length. $\operatorname{LM}(10)$ is the ARCH LM test at lag 10. It is distributed as $\chi^{2}(q)$ where $q$ is the lag length. ${ }^{* *}$ indicates that the null hypothesis is rejected at $5 \%$ level. 
Table 10: Estimates of volatility models

\begin{tabular}{|c|c|c|c|c|}
\hline & $\operatorname{GARCH}(1,1)^{a}$ & IGARCH & FIGARCH $^{d}$ & $\mathrm{HYGARCH}^{e}$ \\
\hline \multicolumn{5}{|c|}{ OPEC: outlier-corrected data } \\
\hline Paramete & & & & \\
\hline$\alpha$ & $n c$ & $0.080527^{*}$ & & \\
\hline$\beta$ & $n c$ & 0.919473 & $n c$ & $n c$ \\
\hline$\alpha+\beta$ & $n c$ & 1 & & \\
\hline$\phi$ & & & $n c$ & $n c$ \\
\hline$d$ & & & $n c$ & $n c$ \\
\hline$k$ & & & & $n c$ \\
\hline \multicolumn{5}{|c|}{ In-sample criteria ${ }^{b}$} \\
\hline LL & $n c$ & -12920.083 & $n c$ & $n c$ \\
\hline AIC & $n c$ & 3.744193 & $n c$ & $n c$ \\
\hline HQ & $n c$ & 3.747166 & $n c$ & $n c$ \\
\hline RCL & $n c$ & 3.744411 & $n c$ & $n c$ \\
\hline \multicolumn{5}{|c|}{ Residuals tests $^{c}$} \\
\hline$Q(10)$ & $n c$ & $17.5234^{* *}$ & $n c$ & $n c$ \\
\hline$Q^{2}(10)$ & $n c$ & $16.2356^{* *}$ & $n c$ & $n c$ \\
\hline $\operatorname{LM}(10)$ & $n c$ & 1.9769 & $n c$ & $n c$ \\
\hline
\end{tabular}

Notes: $n c$ means "not computed". ${ }^{a}$ The condition for existence of the fourth moment of the GARCH is not observed (Ling and McAleer, 2001). ${ }^{d}$ Positivity constraints of the FIGARCH specification are not valid (Conrad and Haag, 2006). ${ }^{e}$ Positivity constraints of the HYGARCH specification are not valid (Conrad, 2010). ${ }^{b}$ LL is the log-likehood value, AIC, HQ and RCL correspond to the Akaike, Hannan-Quinn and Rissanen criteria, respectively. ${ }^{c} Q(10)$ and $Q^{2}(10)$ are respectively the Box Pierce statistics at lag 10 of the standardized and squared standardized residuals. They are asymptotically distributed as $\chi^{2}(k)$ where $k$ is the lag length. $\operatorname{LM}(10)$ is the ARCH LM test at lag 10. It is distributed as $\chi^{2}(q)$ where $q$ is the lag length. ${ }^{* *}$ indicates that the null hypothesis is rejected at $5 \%$ level. 
Table 11: Estimates of volatility models

\begin{tabular}{|c|c|c|c|c|}
\hline & $\operatorname{GARCH}(1,1)^{a}$ & IGARCH & FIGARCH $^{d}$ & HYGARCH $^{e}$ \\
\hline \multicolumn{5}{|c|}{ WTI: original data } \\
\hline Paramete & & & & \\
\hline$\alpha$ & $n c$ & $0.083692^{*}$ & & \\
\hline$\beta$ & $n c$ & 0.916308 & $n c$ & $n c$ \\
\hline$\alpha+\beta$ & $n c$ & 1 & & \\
\hline$\phi$ & & & $n c$ & $n c$ \\
\hline$d$ & & & $n c$ & $n c$ \\
\hline$k$ & & & & $n c$ \\
\hline \multicolumn{5}{|c|}{ In-sample criteria ${ }^{b}$} \\
\hline LL & $n c$ & -14893.7 & $n c$ & $n c$ \\
\hline AIC & $n c$ & 4.316005 & $n c$ & $n c$ \\
\hline HQ & $n c$ & 4.317030 & $n c$ & $n c$ \\
\hline RCL & $n c$ & 4.316226 & $n c$ & $n c$ \\
\hline \multicolumn{5}{|c|}{ Residuals tests ${ }^{c}$} \\
\hline$Q(10)$ & $n c$ & $12.7735^{* *}$ & $n c$ & $n c$ \\
\hline$Q^{2}(10)$ & $n c$ & $15.8145^{*}$ & $n c$ & $n c$ \\
\hline $\operatorname{LM}(10)$ & $n c$ & $1.5600^{* *}$ & $n c$ & $n c$ \\
\hline
\end{tabular}

Notes: $n c$ means "not computed". ${ }^{a}$ The condition for existence of the fourth moment of the GARCH is not observed (Ling and McAleer, 2001). ${ }^{d}$ Positivity constraints of the FIGARCH specification are not valid (Conrad and Haag, 2006). ${ }^{e}$ Positivity constraints of the HYGARCH specification are not valid (Conrad, 2010). ${ }^{b}$ LL is the log-likehood value, AIC, HQ and RCL correspond to the Akaike, Hannan-Quinn and Rissanen criteria, respectively. ${ }^{c} Q(10)$ and $Q^{2}(10)$ are respectively the Box Pierce statistics at lag 10 of the standardized and squared standardized residuals. They are asymptotically distributed as $\chi^{2}(k)$ where $k$ is the lag length. $\operatorname{LM}(10)$ is the ARCH LM test at lag 10. It is distributed as $\chi^{2}(q)$ where $q$ is the lag length. ${ }^{* *}$ indicates that the null hypothesis is rejected at $5 \%$ level. 
Table 12: Estimates of volatility models

\begin{tabular}{|c|c|c|c|c|}
\hline & $\operatorname{GARCH}(1,1)^{a}$ & IGARCH & FIGARCH $^{d}$ & HYGARCH $^{E}$ \\
\hline \multicolumn{5}{|c|}{ WTI: outlier-corrected data } \\
\hline \multicolumn{5}{|c|}{ Parameters } \\
\hline$\alpha$ & $n c$ & $0.065640^{* *}$ & & \\
\hline$\beta$ & $n c$ & 0.934360 & $n c$ & $n c$ \\
\hline$\alpha+\beta$ & $n c$ & 1 & & \\
\hline$\phi$ & & & $n c$ & $n c$ \\
\hline$d$ & & & $n c$ & $n c$ \\
\hline$k$ & & & & $n c$ \\
\hline \multicolumn{5}{|c|}{ In-sample criteria ${ }^{b}$} \\
\hline LL & $n c$ & -14622.221 & $n c$ & $n c$ \\
\hline AIC & $n c$ & 4.237352 & $n c$ & $n c$ \\
\hline HQ & $n c$ & 4.238377 & $n c$ & $n c$ \\
\hline RCL & $n c$ & 4.237570 & $n c$ & $n c$ \\
\hline \multicolumn{5}{|c|}{ Residuals tests $^{c}$} \\
\hline$Q(10)$ & $n c$ & $9.18690^{* *}$ & $n c$ & $n c$ \\
\hline$Q^{2}(10)$ & $n c$ & $14.5041^{* *}$ & $n c$ & $n c$ \\
\hline$L M(10)$ & $n c$ & $1.4476^{* *}$ & $n c$ & $n c$ \\
\hline
\end{tabular}

Notes: $n c$ means "not computed". ${ }^{a}$ The condition for existence of the fourth moment of the GARCH is not observed (Ling and McAleer, 2001). ${ }^{d}$ Positivity constraints of the FIGARCH specification are not valid (Conrad and Haag, 2006). ${ }^{e}$ Positivity constraints of the HYGARCH specification are not valid (Conrad, 2010). ${ }^{b}$ LL is the log-likehood value, AIC, HQ and RCL correspond to the Akaike, Hannan-Quinn and Rissanen criteria, respectively. ${ }^{c} Q(10)$ and $Q^{2}(10)$ are respectively the Box Pierce statistics at lag 10 of the standardized and squared standardized residuals. They are asymptotically distributed as $\chi^{2}(k)$ where $k$ is the lag length. $\operatorname{LM}(10)$ is the ARCH LM test at lag 10. It is distributed as $\chi^{2}(q)$ where $q$ is the lag length. ${ }^{* *}$ indicates that the null hypothesis is rejected at $5 \%$ level. 